\title{
Beautification of Pokhara City with a Special Focus on Phewa Lake and Lakeside Area
}

\author{
Prashidha Khatiwada*, Rabindra Adhikari \\ This paper is dedicated to the memory of the Hon. Rabindra Adhikari, Minister for Culture, Tourism and Civil Aviation, Nepal \\ Department of Infrastructure Engineering, The University of Melbourne, Parkville, Victoria, Australia
}

Corresponding Author: khatiwada.prashidha@unimelb.edu.au

Received on: $28^{\text {th }}$, Dec., 2020

Accepted for publication: $10^{\text {th }}$ March., 2021

\begin{abstract}
Pokhara is one of the rapidly growing cities of Nepal. It is the second-largest metropolitan city after Kathmandu. Because of the renowned temples, monasteries, lakes, adventure sports, and being close to the well-known Annapurna Range, it is considered as the tourism capital of Nepal. Millions of tourist visit this naturally gifted city every year contributing to considerable economic development. This economic prospect has attracted thousands of migrants every year leading to $67 \%$ growth in population in the last decade. The rapid population growth and urbanization without long-term planning and firm regulation have severely affected the development of sustainable infrastructure, preservation of the public space and natural resources. This has further impacted the tourism, economy, health and wellbeing, environment, and social aspect of the city. This article aims to generate strategies for retaining and improving the natural beauty of the city (focusing on the Phewa Lake area) by enhancing the economy and environment, rejuvenating social and cultural values, elevating the health and wellbeing of the people, and strengthening and promoting sustainable development. In this article, literature reviews, interviews, and field surveys were undertaken and four major improvements/developments are recommended for the beautification of Pokhara City. The recommendations are: preservation and development of open space into self-sustaining cohesive community parks, citizen-centred urban development, improvement of current transport infrastructure, and conservation of natural resources such as water, vegetation, and landscape.
\end{abstract}

Keywords: Phewa Lake, Conservation of Lake, Public Space, Community Parks, Sustainable City.

\section{Introduction:}

Pokhara is the capital of Gandaki Province of Nepal. It is the largest metropolitan city in terms of area and the second-largest in terms of population (about 421,000 in 2020) of Nepal. It is located about 200 kilometres west of the capital, Kathmandu with an altitude range of 827 meters to 1,740 meters. Pokhara especially the Phewa Lake area is not only known for its panoramic views of Annapurna, Dhaulagiri and Lamjung Himalayan ranges but also with the renowned temples, monasteries and pagodas, lakes, and adventure sports centre. Because of these features, it has been considered the most beautiful destination for tourist in the world. On the other side, the natural beauty and tourismbased economic development and prosperity have led to rapid migration and population growth in the past decade [1]. The population has increased by more than two-thirds in the last decade [2]. The rapid population growth and urbanization have severely affected the land use, open space, ecology, and natural beauty of the 
city [1]. This has further impacted the tourism, economy, health and wellbeing, environment, and social and cultural aspect of the city.

The beautification of the city in the world has been the focus since the mid-18th century. In 1853 , a village beautification society was formed in the United States [3]. With time, the purpose and strategy of city beautification have changed and evolved significantly [4]. The strategies of the early 20th century were focused on monumental public spaces, street beautification, and classical architecture, with an emphasis on aesthetic and recreational values [4]. During this period, improving the living conditions of the urban populace and providing moral and civic virtue through high aesthetics were considered important strategies [4]. Then the beautification of the city evolved into an idea of combining environmental, aesthetic, recreational, and leisure amenities: museums, waterfront parks, open-air shopping centres, and other public spaces. Recently, the beautification of the city is more focused on sustainability and livability [4]. The economic and sustainable infrastructure development incorporating the communities to be served in the planning, decision-making, implementation and management processes are key to the sustainability of the city [5]. For a city to be self-sustaining, infrastructures such as water supply, sanitation facilities, drainage, urban roads, solid waste disposal facilities, and land management need to be developed effectively [5]. In similar regard, wellbeing parameters such as income, consumption, public space and amenities, level of environmental pollution, and parameters of quality of life such as quantity and quality of climate and natural beauty and public recreation, education and healthcare amenities are considered as the major indicator of the livable and happy city [6].

The transformation of a haphazardly developing city to a sustainable and livable city is a challenging task. As public green spaces, parks and recreation areas are considered as the important factors in beautifying a city, beautification of Pokhara City is even more challenging due to limited and depleting open space [1]. Focusing on the vision of a sustainable and livable city, this study recommends four major improvement/development targets for the beautification of Pokhara City. The first recommended target is the preservation and development of open space into self-sustaining cohesive community parks, recreational parks and leisure amenities. The second target is to include participation and involve citizens in all aspects of urban development. The third recommended target is to improve and develop transport infrastructure more aesthetically and sustainably. The fourth target is to preserve natural resources such as water, vegetation, and landscape. These four developments are primarily related to the improvement of tourism, economic, social, cultural, environmental, and health and wellbeing aspects of the city.

\section{Research Methodology:}

The research methodology mainly consists of two methods: interview and field studies. Interviews were conducted with residents and experts working in the field of land, water and urban planning divisions to understand their opinion of the beautiful city and improvements that are needed to beautify Pokhara City. The interview responses were analyzed based on the sustainability and livability parameters as highlighted in Section 1, and finally, a desktop survey and field study was undertaken for preparing the proposal.

\subsection{Interview:}

To gain a better understanding of the opinion of the residents and experts about the current problems of Pokhara City and what are their future expectation about the city and from the city, semi-structured interviews were conducted. The following set of questions were asked during the interview:

- On a scale of 10, what score will you give to Pokhara especially the Phewa Lake area compared to your beautiful dream city?

- What three key improvements are needed to transform Pokhara into a sustainable, livable and beautiful city?

- Can you highlight one specific development that you feel is required to bring each improvement?

The interviews were conducted with 5 permanent residents from the Lakeside area, and 5 technical experts. A permanent resident was defined as someone who had stayed with his/her 
family in Pokhara for at least 15 years. Similarly, a technical expert was defined as someone working in the public sectors of Pokhara for at least 5 years in the fields including tourism, urban, land, and water development. In the case of permanent residents, interviews were conducted at their home. Whereas, with experts, interviews were taken at their offices. In both cases, the interviews lasted approximately 12 minutes. The responses were recorded by note-taking.

\subsection{Google Earth Survey and Field Study:}

Based on the responses obtained from interviews, several improvement options were considered for the Phewa Lake area of Pokhara City. Those options related to sustainability and livability were selected. Then a field visit was undertaken including the Phewa Lake area, it's water inflow sources, the Rani Ban area, public open spaces, parks, roads, and the major infrastructures in the Lakeside (Damsite, Baidam, Dihikopatan, Pame and Khapaudi area). The Google Earth software (Version 7.1) was used for the preliminary measurement of the water covered area of Phewa Lake, the area of nearby open spaces, and the length and elevation of Mansawar Road or Phewa Marga. Furthermore, manual counting of the motorized traffic volume at Mansawar Road was conducted near Nareshwar Bus Stop for the design of Modern Mansawar Road as discussed in Section 3.4 .

\section{Result and Discussion:}

Based on the responses of interviews, on average Pokhara received $6 / 10$ scores when compared to the hypothetical dream city of the interviewee. Similarly, the responses highlighted the need for development/improvements of the transport and other physical infrastructure, preservation of public space and Phewa Lake, community cohesion, development of recreational and leisure amenities, and responsible and smart citizens. Likewise, the interviewee highlighted developments such as better quality and safe road, passenger-friendly bus, electric bus, clean city, efficient waste disposal facility, recreational parks, amusement parks, parks and garden near home, clean Phewa Lake and Khola-Nalas (creeks), public meeting space, shopping centres and gaming zones, artificial beach, aquarium, water park, education, and jobs. The responses are summarized in Table 1. Based on these responses four major developments were proposed. These development are discussed in Section 3.1 to 3.4.

\subsection{Phewa Park:}

Phewa Park consisting of four components: Living Park (Jaivik Kunj), Water Park (Jal Kunj), Beach Park (Tat Kunj), and Amusement Park (Leela Kunj) is proposed for utilising public space for recreation and entertainment, enhancing tourism and economy, improving ecology, rejuvenating social and cultural values, improving health and wellbeing of the people, and beautifying Pokhara City. The Camping Site nearby Hallanchok as shown in Fig.1 is recommended for the park due to it's positioning and suitability. From Camping Site, the thick vegetation of Rani Ban, beautiful Phewa Lake, World Peace Pagoda, Tal Barahi Temple, Pame area, and Paragliding Landing Spot are visible and the site is suitable for the park because of its proximity to Phewa Lake. The main components of Phewa Park and it's features are shown in Fig. 2. The design requirements are validated with the guidelines for urban open space presented in [7].

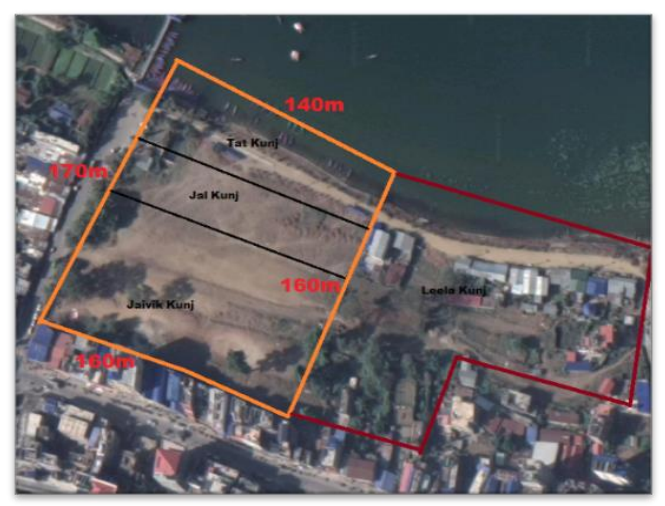

Figure 1: Google Earth image of the Camping Site (dimensions are approximate only). 
Table 1: Summary of responses obtained from the interview.

\begin{tabular}{|c|c|c|c|}
\hline Responder & $\begin{array}{c}\text { Score } \\
\text { out of } 10\end{array}$ & Three key improvements & Specific developments \\
\hline 1 & 7 & $\begin{array}{c}\text { Economic, natural, and } \\
\text { infrastructure developments }\end{array}$ & $\begin{array}{l}\text { More jobs, preservation of lakes and } \\
\text { open space, and better roads }\end{array}$ \\
\hline 2 & 5 & $\begin{array}{l}\text { Physical infrastructure, } \\
\text { preservation of nature, and } \\
\text { recreational amenities }\end{array}$ & $\begin{array}{c}\text { Better quality road, cleaner Phewa Lake, } \\
\text { and shopping centres }\end{array}$ \\
\hline 3 & 8 & $\begin{array}{l}\text { Physical infrastructure, } \\
\text { community cohesion, and } \\
\text { responsible and smart citizens }\end{array}$ & $\begin{array}{l}\text { Passenger friendly bus, parks near home, } \\
\text { and education }\end{array}$ \\
\hline 4 & 4 & $\begin{array}{l}\text { Preservation of Phewa Lake, } \\
\text { preservation of public space, } \\
\text { and leisure amenities }\end{array}$ & $\begin{array}{c}\text { Clean Phewa Lake, recreational parks, } \\
\text { and amusement parks }\end{array}$ \\
\hline 5 & 6 & $\begin{array}{l}\text { Tourism and economy, } \\
\text { preservation of natural } \\
\text { resources, and community } \\
\text { cohesion }\end{array}$ & $\begin{array}{l}\text { More jobs, clean Phewa Lake and Khola- } \\
\text { Nala, and cultural development }\end{array}$ \\
\hline 6 & 7 & $\begin{array}{c}\text { Road and public transport, } \\
\text { preservation of Phewa Lake } \\
\text { and water bodies, and waste } \\
\text { management }\end{array}$ & $\begin{array}{l}\text { Passenger friendly and electric bus, } \\
\text { better Phewa Lake, and better waste } \\
\text { disposal facility }\end{array}$ \\
\hline 7 & 4 & $\begin{array}{l}\text { Economic development, } \\
\text { preservation of nature, and } \\
\text { infrastructure developments }\end{array}$ & $\begin{array}{l}\text { More jobs and secured tourism, } \\
\text { preservation of lakes and open space, } \\
\text { and better road }\end{array}$ \\
\hline 8 & 6 & $\begin{array}{c}\text { Physical infrastructure, } \\
\text { preservation of public space, } \\
\text { development of recreational } \\
\text { spaces }\end{array}$ & $\begin{array}{l}\text { Shopping centres and gaming zones, } \\
\text { artificial beach, aquarium, and water } \\
\text { park }\end{array}$ \\
\hline 9 & 7 & $\begin{array}{l}\text { Physical infrastructure, } \\
\text { community cohesion, and } \\
\text { more responsible citizens }\end{array}$ & $\begin{array}{l}\text { Better hospitals, parks near home, and } \\
\text { awareness among people }\end{array}$ \\
\hline 10 & 6 & $\begin{array}{c}\text { Improvement in public open } \\
\text { space, education, and } \\
\text { healthcare }\end{array}$ & $\begin{array}{l}\text { Recreational parks, high-speed internet, } \\
\text { and better hospitals }\end{array}$ \\
\hline
\end{tabular}

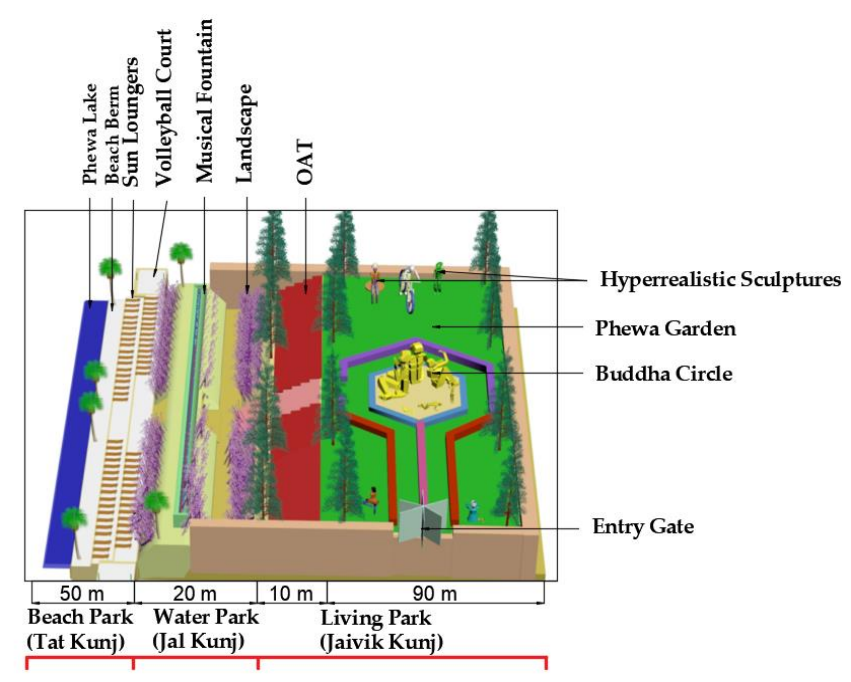

Figure 2: Proposed Phewa Park and it's detailing. 


\subsubsection{Living Park (Jaivik Kunj)}

At the entrance of Phewa Park, the Living Park consisting of various features and representing the lifestyle and cultural aspects of Pokhara is proposed. It consists of four major components: the Buddha Circle, Hyperrealistic Sculptures, Phewa Garden, and Open Air Theatre (OAT). These components are discussed below:

- The Buddha Circle (Circle of Life): spiritual development has been considered as one of the main contributing factor in health and wellbeing [8]. To incorporate the benefit of spirituality, the "Buddha Circle" is proposed. The circle will consist of different stages of the life of Gautam Buddha demonstrated in a circular arrangement on a hexagonal base as shown in Fig.2. The Buddharupa (statue of Buddha) will consist of five stages of Buddha's life: birth (mysterious 7paila/footsteps), childhood, early adulthood (royal life), middle-age (enlightenment), and life after enlightenment or teaching stage symbolising harmony between man, nature, people and religion, and essence of life [9].

- Hyperrealistic Sculptures: the park is proposed to host super-realistic sculptures demonstrating different themes. For example, a female and male dancer posing local cultural dance, Gorkha Army holding "Khukuri", fisherman sitting on the stone and holding a fishing rod, a cyclist etc. The hyperrealistic sculptures will not only be a new introduction to the city but also will promote and restore cultural values. For example, the sculpture showing male and female dancer will bring cultural vibrancy, the sculpture posing the great Gurkhas will demonstrate the honesty and assiduousness of the local people, and the fisherman sculpture will represent and preserve the once-popular fishing culture. The sculpture will promote cultural and recreational activities which are proven as beneficial for health and wellbeing [10]. Similarly, the sculpture of the local cyclist can help in promoting cycling culture and contribute to the health and wellbeing of people [11-12]. These hyperrealistic sculptures will not only promote the culture, health, and wellbeing but also contribute to beautifying the city and improving tourism and the economy.

- Phewa Garden: it is a planned space set aside for the display, and for the cultivation, and enjoyment of native plants (plants of different types, heights, colours, textures, and fragrances to create interest and delight the senses). It is proposed to be the combination of the floral band (band of different types of indigenous flowers), vegetables and herbs band (assortment of typical local and indigenous vegetables, and herbs grown and decorated in rows), fauna (humanfriendly butterflies, birds, squirrels etc.), vertical garden (covered with vegetation forming patterns representing the map of Nepal) and landscape: paths, rockeries, walls and sitting areas as shown in Fig. 2. The combination of natural elements: flora and fauna, soil, water, air, and light, and constructed elements: paths, patios, decking, sculptures, and lights will provide a vibrant environment to the park. The Phewa Garden will provide aesthetic, functional, recreational, economic, and environmental significance to the city.

- Open Air Theater (OAT): OAT is the transitional space between the "Jaivik Kunj" and the rest of the Phewa Park. It is the space for sunbathing and enjoying the elegant view of "Jal Kunj" consisting of a fish aquarium and "Phewa Aestic Fountain". The OAT will consist of about 5-6 steps (about $45 \mathrm{~cm}$ rise and $1 \mathrm{~m}$ run) covered by slate stone (local stone of Nepal) providing a sitting space for about 1200 spectator.

\subsubsection{Water Park (Jal Kunj)}

The Water Park consists of "Phewa Aestic Musical Fountain (PAMF)". PAMF is a type of animated fountain combined with water, light and music portraying the culture and characteristics of Pokhara. PAMF is achieved by employing the effects of timed sound waves and 
timed light (including laser) against water particles. The water refracts and reflects the light, and in doing so three-dimensional images are produced. The example of the demonstration of the Himalayas of Nepal through PAMF is shown in Fig. 3

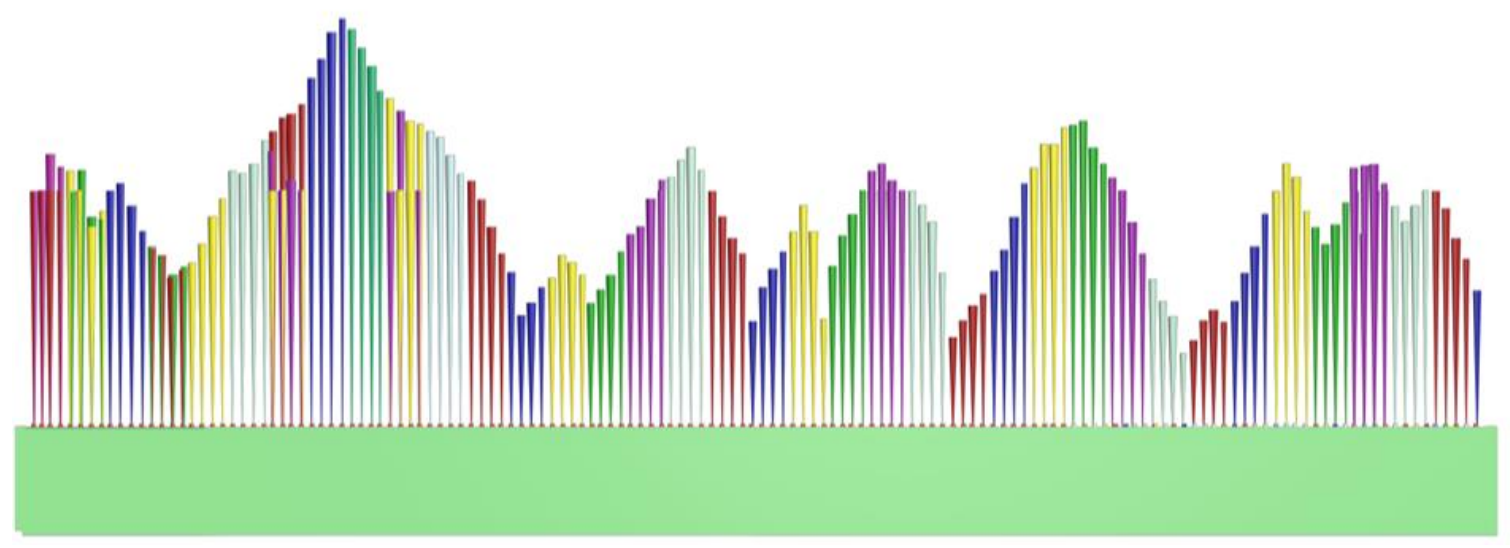

Figure 3: Phewa Aestic Musical Fountain (PAMF) portraying the Himalayas of Nepal.

PAMF will not only add colour and music to the city but also contribute to the purification of Phewa Lake's water. As the water is directly pumped and recycled instantly to Phewa Lake, the aeration of water in the air will help in improving the water quality [13]. Based on literature review and field survey, PAMF may consist of 150 channels shooting 5 tons of water per minute, 1000 LED nozzles for lighting, a linear water screen of 8.5 meters high and 5.75 meters wide with a 100-meter long water cascading area [14]. PAMF will contribute to the cultural, tourism and economic development of the city.

\subsubsection{Beach Park (Tat Kunj):}

The Beach Park will consist of "Phewa Beach" made of local decorative sand, gravel, shingle, pebbles, and cobblestones. It will give locals and tourists an entertaining and athletic environment. The soothing qualities of a beach and the pleasant environment offered to the beachgoer will be replicated in it as shown in Fig. 3. Beach lovers could enjoy a musical fountain and garden on the backside, and a landscape and volleyball court on the left and right sides. While sunbathing in the loungers, they can enjoy the mesmerizing view of Phewa Lake, Rani Ban, World Peace Pagoda, and the reflection of the Himalayas. They can sit under the palm trees, and play with sand, and pebbles.

At the starting of the Tat Kunj and below the musical fountain, a semi-underground structure is proposed for facilitating changing rooms, showers, hospitality venues, information desk, mini-museum, and mini fish aquarium.

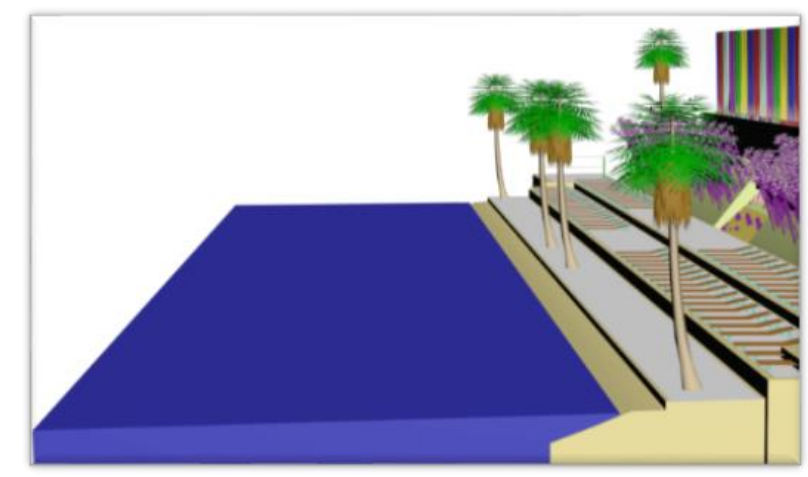

Figure 4: Perspective view of Phewa Beach

\subsubsection{Amusement Park (Leela Kunj):}

The "Leela Kunj" will contain a roller coaster and other related amusement equipment. It will contribute to the recreation and entertainment aspect and will attract tourist leading to revenue generation. It will give Pokhara recognition as a modern and vibrant city in Nepal.

\subsection{Samudayik Maulik Uddhan/Sahari Chautari (Community Park):}

Samudayik Maulik Uddhan (SMU) also known as Sahari Chautari or Community Park is a public open area decorated and embellished for the community by the people of the community using skills, experience and originalities of the community. The working modality and the benefits of SMU are shown in Fig. 5. This seminatural space is proposed for bringing 
productivity and creativity to the community, for sharing, and bringing positive changes in the connecting people through collaboration and health and wellbeing of the people.

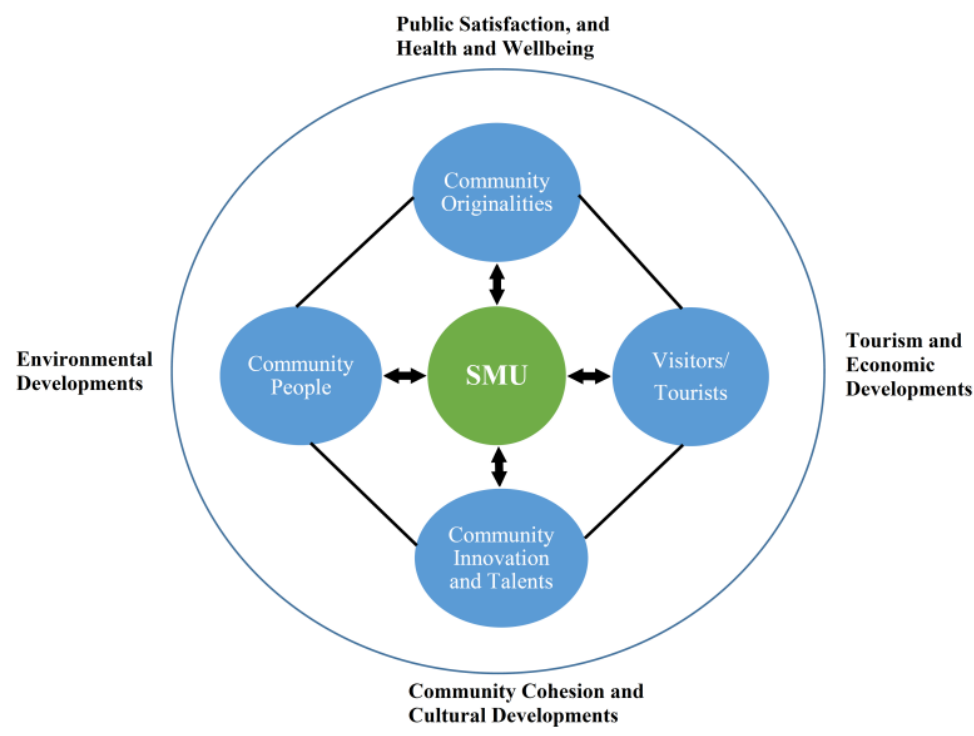

Figure 5: Working modality of Samudayik Maulik Uddhan (SMU) system and it's benefits.

\subsubsection{SMU leading to sustainable Pokhara}

- Community cohesion and cultural developments: as the theme of the SMU is ultra-focused on connecting and collaborating with people of the community, it will contribute to establishing equity and resolving social discriminations, and in improving cultural values. People will evoke by the feeling of unity.

- Public satisfaction, and health and wellbeing: SMU uses the physical, mental, and creative capacities of the people and offers them social cohesiveness, cultural activities, a place for meditation and rest, a peaceful place, place for productive conversation and discussions, inspiration, and restore psychophysical equilibrium, finally creating public satisfaction, and health and wellbeing benefits. Contemporary studies have also found the contribution of an urban community garden in stressreduction and mental health [15-17].

- Environmental developments: the plantation of trees, flowers, vegetables, and herbs will contribute to reducing air pollution and greenhouse gas, and in enhancing the environment.

- Tourism and economic developments: the tourism, and health and wellbeing benefit of the SMU will provide direct and indirect economic benefits and contribute to the city's economy.

\subsubsection{Typical features of Samudayik Maulik Uddhan (SMU)}

- SMU will use the local materials, skills, workmanship and local natural and cultural theme such as playing spaces, trees, herbs, floral, and vegetable garden, cultural plays etc. It shall demonstrate community originalities.

- The development will capitalize on the abundant natural features of the existing site.

- SMU will be planned, designed, constructed, maintained and regulated by the community stakeholders. All the investment will be managed within and by the community.

- Several SMU will be inter-linked through street linkages and networks. 
- SMU will incorporate community cohesiveness as well as a tourist attraction.

- Visual privacy and noise barrier shall be created through design and landscaping for preventing noise and disturbance to the neighbourhood.

\subsubsection{Some common indigenous and popular specimens recorded from the field study}

Example of some of the indigenous and popular specimens recorded during the field study, that can be used for decorating SMU are listed below.

- Baja and other musical instruments,

- Indigenous fruits: banana, pomegranate, pineapple etc., flowers: Lalupate (Euphoria), marigold, Jahi-Juhi-Chameli, Parijat etc., vegetables: tomatoes, chillies, mustards etc., and herbs: Sisnu, Niyale bamboo, Dubo, ferns etc.,

- Innovative technical and mechanical instrument/specimen

created/manufactured by local students,

- Adventurous instruments,

- Repaired and ornamented recycled boats and paddle designed in native styles,

- Specimens such as Halo-Juaa and DhikiJato,

- Clay pots and pottery collection, pottery water fountain with lighting, lights, painting, crafts, statues, magazines, and other artistic specimens prepared by children,

- Collecting a typical specimen from visitors for symbolizing wishes and fortune.

\subsubsection{Prospect of SMU in Pokhara}

Through a field survey and study of the land survey report [18], Pokhara Metropolitan has about 8983 ropanis of public and government land which has the potential of developing into SMU. If this amount of land can be revived through SMU, it will help in developing a strong community and unified city. One of the proposed SMU: Nareshowar Samudayik Maulik Uddhan, located in Baidam, Pokhara is provided in Fig. 6.

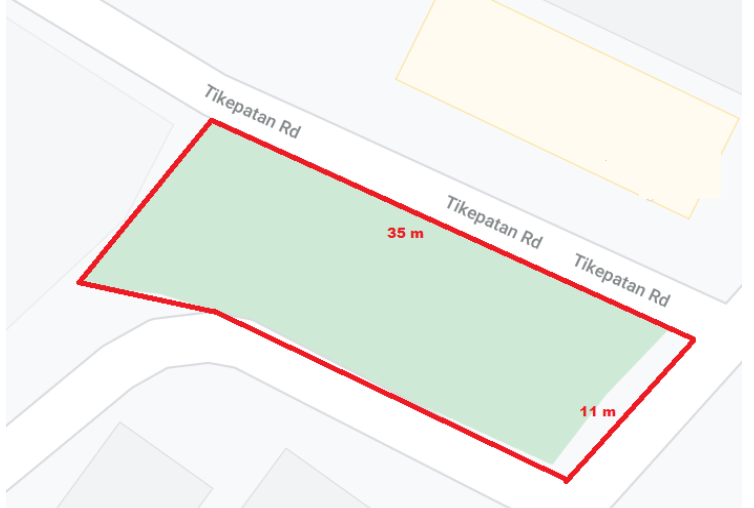

Figure 6: Google Map view of the Nareshwar Samudayik Maulik Uddhan with approximate plot dimensions determined from field measurement.

\subsection{Conservation of Phewa Lake:}

Phewa Lake is a stream-fed freshwater lake formed by primary inflows of Harpan Khola, Phirke Khola, Miya Khola, and Bulaudi Khola with a total catchment area of $122.53 \mathrm{~km}^{2}$. The maximum length, width and depth of the lake is approximately $4 \mathrm{~km}, 2 \mathrm{~km}$, and $24 \mathrm{~m}$, respectively. From the site visit and interviews, it is found that the lake is losing its size due to encroachment, siltation, vegetation lost in the catchment area, and waste disposal.

\subsubsection{Reduction in the Size of Phewa Lake:}

The GPS imagery data of Phewa Lake over the last 16 years shows a significant reduction in the water covered area. The approximate reduction from the year 2004-2020 were estimated using Google Earth area measurement tools and the created boundaries are shown in Fig.7. The water covered area reduced from $4.32 \mathrm{~km}^{2}$ to $4.26 \mathrm{~km}^{2}$ from 2004 to $2008,4.21 \mathrm{~km}^{2}$ to 2012 , and $4.00 \mathrm{~km}^{2}$ to 2020 . The reduction is found to be about $7.4 \%$ in the last 16 years, and about 5 $\%$ in the last 8 years. If preventive measures are not taken on time, the lake may dry up by about 200 years. From a field visit of the surrounding, two major causes were identified: human encroachment and waste disposal in the vicinity of the lake, and siltation (prominent in Harpan Khola, Firke Khola, and other small creeks) and vegetation loss of the catchment area. Disposal of municipal waste was found to not only cause the reduction in the size of the lake but also serve as a major pollutant and cause of ecological damage to the lake. The lack of vegetation in the catchment area was found to depreciate the quality of the watershed and to 
cause a landslide. The discharge of silts due to landslide and water runoff was found to reduce the quantity of water in the lake by covering the basin and the periphery.
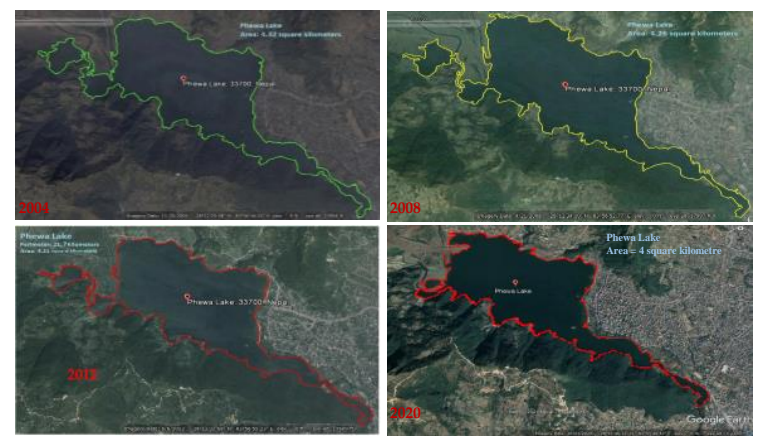

Figure 7: Google Earth images of the boundary of the Phewa Lake for the year 2004, 2008, 2012, and 2020.

\subsubsection{Phewa Lake Water Pollution:}

Pollution of Phewa Lake was observed to have a direct impact on the natural beauty of the lake. From the site visit, the major sources of pollutant were able to be tracked to city drainage, human activities such as bathing and washing clothes, disposal of waste to the creeks and major inflows, dumping of waste by the visitors, discarded boats, and discharge of silts from the inflows. Water hyacinths were also observed to affect the lake ecosystem and to cause visual pollution and unpleasant view of the lake. The common type of wastes found in the vicinity of the lake was hard wastes such as glass bottles, scarp glass, metals, and electronic wastes, paper and plastic wastes, construction wastes, clinical wastes, and food wastes. The picture of the disposed waste taken during the field visit is shown in Fig. 8.
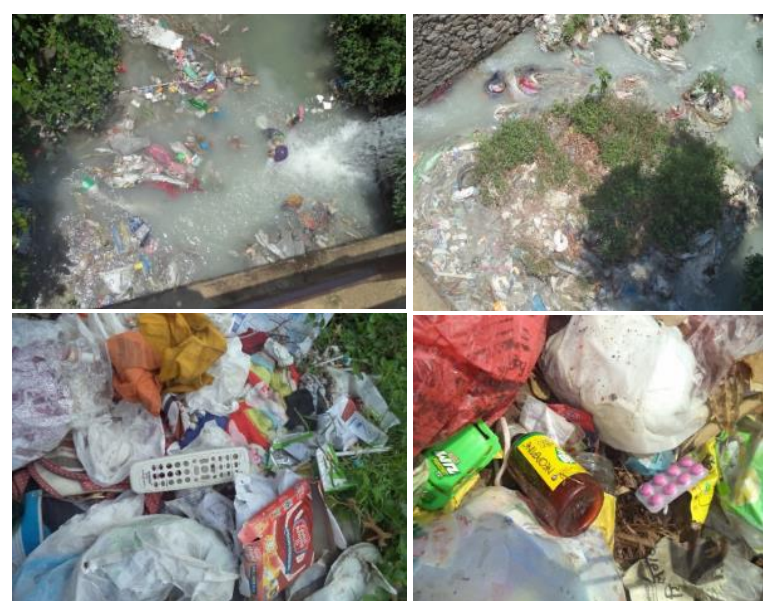

Figure 8: Common waste types observed in Bulaudi Khola (vicinity of Phewa Lake).
The possible impacts of the pollution of Phewa Lake are detrimental effects in the ecosystem, economic impacts, impacts on physical infrastructure such as downstream hydropower, irrigation channel, and impacts to the Tal Barahi Temple.

\subsubsection{Conservation Strategies:}

Three major strategies: silt control, hyacinth control, and waste control are proposed for the conservation of Phewa Lake. These strategies are discussed below.

- Silt control through check dams: the construction of a check dam to the upstream of the inflows can be used for reducing flow velocity and controlling soil erosion. Future studies are recommended for the detail feasibility study of the check dam.

- Hyacinth control: water hyacinth infestation is the major cause of visual pollution of the Phewa Lake, difficulties for boating and fishing, clogging of irrigation canals, reduction in dissolved oxygen, blocking of light, aggravation of the lake ecosystem, and mosquitoes infestation. As large number of human manpower is currently used in manually removing hyacinth from the lake, a much safer and efficient mechanical harvester for extracting and removing hyacinth is recommended. The example of the mechanical harvester is shown in Fig.9. The recovered hyacinth may then be transformed into ethanol fuel [19-20], which can be used to run ecofriendly vehicles. Similarly, or water hyacinth may be used as a raw material for handicrafts, fabrics, and paper manufacturing.

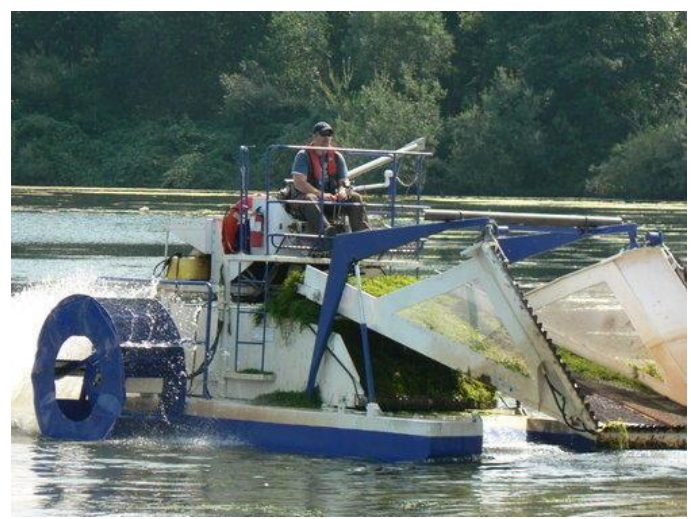

Figure 9: Hyacinths extraction using mechanical harvester [21]. 
- Waste treatment: the water discharged directly into Phewa Lake can be treated effectively and economically before discharging into the lake using screening, aeration and algal treatment methods. The treatment will contribute to managing quality water, enhancing aesthetics, improving the ecosystem, and controlling hyacinths growth. Through screening, the large solids waste can be extracted and recycled/removed. Similarly, through aeration, biological or chemical wastes such as sulfur dioxide and volatile organic compounds (VOCs) can be removed [22]. A waterfall and air diffusers such as fountains can be used for water aeration. Furthermore, using algal treatment (aerobic treatment of waste), nitrogen, phosphorous, heavy metals, and several toxic compounds can be removed, and biomass and bioenergy can be recovered [23-24].
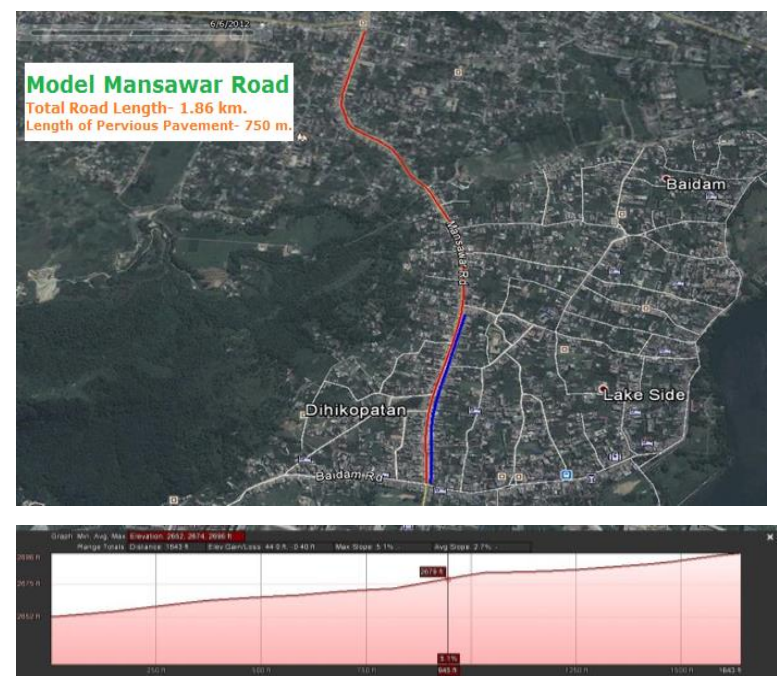

Figure 10: Road connectivity map of MMR and it's surface slope $(5.1 \%)$ determined using Google Earth [25].

\subsection{Modern Mansawar Road (MMR):}

Modern Mansawar Road (MMR) is a $1.86 \mathrm{~km}$ long, advanced and smart modern road between Zero K.M. to the Hallanchok section of existing Mansawar road which is shown in Fig.10. It is a multi-lane smart sub-arterial road designed to provide safe and efficient movement of traffic from Panchase Marga, Baidam Road, Uday Marg, Tikepatan Road, Gairikhet Marga, and traffic coming from major commercials, residential and tourist centres of Pokhara.

MMR will consist of the dedicated vehicular travel lane, sidewalks, dedicated cycle lanes, parking (vehicular and cycle), transit station, median barriers, solar light, and other landscape structure as shown in Fig. 11. The proposed 750 meters of pervious pavement cycle lane and sidewalks will provide environmental benefits. The central dual carriageway will help to deliver vehicular traffic. For safety and efficiency, sidewalk, cycle land and vehicular lane are designed to have dedicated traffic. The "before" and "proposed" view of the road is shown in Fig. 11.
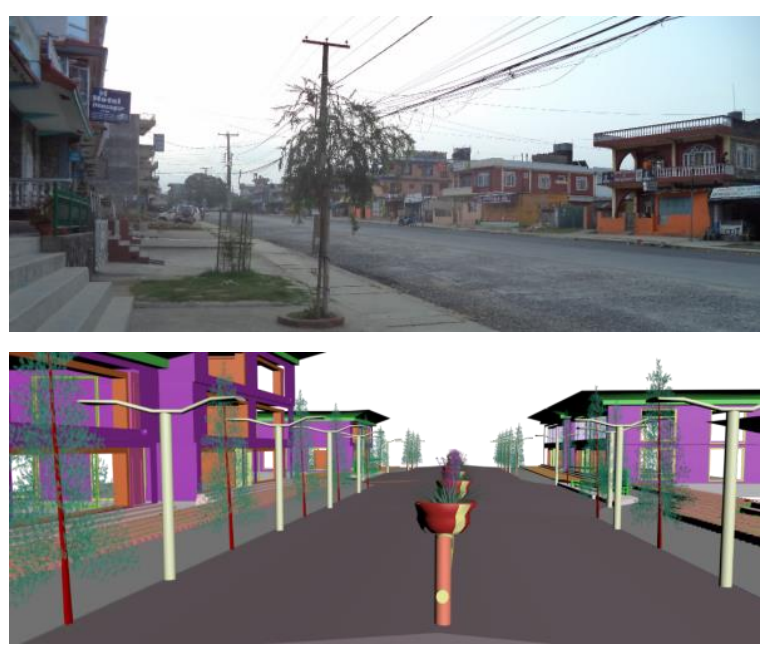

Figure 11: Before (top) and proposed (bottom) views of MMR

- Motorized vehicular lane: A manual counting of traffic volume was conducted during the peak hour ( $9 \mathrm{AM}-10 \mathrm{AM}$ ) from 1st August to 7th August of 2014 based on the passenger car unit provided in [26]. From the counting, the total peak hour traffic volume was found to be $1100 \mathrm{pcu} / \mathrm{hr}$ or $550 \mathrm{pcu} / \mathrm{hr}$ in each direction. Taking into consideration of the future traffic growth, the carriageway is designed for $2150 \mathrm{pcu} / \mathrm{hr}$ in each direction or $1075 \mathrm{pcu} / \mathrm{hr} / \mathrm{lane}$. The proposed capacity is 1.95 times higher than the 2014 demand. The lane width of $3 \mathrm{~m}$ is selected based on the design charts given in [27]. The total width of the road consisting of four lanes (2 lanes in each direction) is $12.5 \mathrm{~m}$ with the $50 \mathrm{~cm}$ central median (steel railing with flowering pot as shown in the design).

- Automated traffic light for vehicle, cyclist, and pedestrian crossing is recommended for safer and efficient flow and transition of vehicles, cyclists and pedestrians.

- Traffic barrier: a flexible barrier consisting of steel railings and flower pots is proposed as a median divider for improving road traffic safety and smoother traffic flow. 
- Drainage: The first $750 \mathrm{~m}$ of the road from Hallanchok will be drained through the pervious pavement of the cycle lane and sidewalk. While the remaining portion of the road will be drained through the gutter placed below the non-porous sidewalk and can be discharged to Firke Khola after treatment.

- Motorized vehicle and cycle parking: offstreet parking will be encouraged in peak hours and on-street parking will be used during happy hours for traffic calming. Convenient and safe bicycle parking/storage will be provided near to transit station (15 bicycle/station) with anti-theft/locking facility. Every commercial building is encouraged to provide cycle parking and a safe storage facility to increase the parking volume.

- Lighting: solar street lighting will be aligned with the tree plantation to establish coordinated streetscapes. Street lighting will accommodate the needs of pedestrians and will be designed to ensure pedestrian comfort and safety.

- Transit station: a transit station is proposed for efficient exchanged of the passenger between different transport modes or between vehicles. Transit station along with waiting amenities are to be provided at designated intersections with sufficient space to include a safe waiting area/shelter, seating facility (for about 20 passengers), cycle parking, and other necessary services such as facilities for disabled and old people, vending machine etc. Display of vehicle arrival timing is highly recommended. A station length of $15 \mathrm{~m}$ with $11 \mathrm{~m}$ length for bus parking (one large bus or two smaller vehicles such as microbus) and $2 \mathrm{~m}$ length at the entry and exit is recommended.

- Landscaping: landscaping along MMR is proposed to include deciduous trees, planted at 7 to 10 meters spacing on both sides of the road. A species that will form a continuous canopy at maturity is recommended. The location of trees should be coordinated with the location of utilities and infrastructure that share the right-ofway. Aesthetic flowers and a flower pot will be provided at the median for decorating MMR. All the components of the road are arranged in such a way to give ultimate safety, easier access, comfort and a pleasing look.

- Sound barriers: the impact of noise will be mitigated through the use of planting, beaming and upgraded fence design. The road surface can be provided with whispered finishing to have anti-noise property.

- Air pollution (dust and smoke) control: use of electric vehicles, plantation, timely cleaning and flushing, minimizing light vehicle/car and encouraging mass passenger vehicle/bus for reducing traffic volume, and banning high carbon emission vehicles are recommended for controlling air pollution.

- Coherent side buildings: the coherent architecture of buildings, such as finish/colour/materials is highly encouraged along with the MMR. The corner buildings are encouraged to have similarly articulated facades on both streets. Window glazing is encouraged to maximize along street frontages while avoiding spandrel, reflective or tinted glass. Showroom, restaurants, galleries, music palaces are encouraged alongside the sidewalks with pedestrian-friendly amenities such as outdoor seating areas and patios in the front and sides of buildings. Primary building entrances will be oriented to the street, with defining architectural elements such as entrance canopies, lighting and awnings.

- Sidewalks: sidewalks are proposed on both sides of the road with an inviting facility for the comfortability of pedestrians. The sidewalk width of 5 feet in the narrower and 6 feet in the wider portion is recommended to allow three people walking side-by-side or passing without any obstructions. The deciduous tree line between the vehicular lane and cycle lane will provide safety to the pedestrian from moving vehicles. The first 600 to 800 meters of the sidewalks from Hallanchok will be paved with porous interlocking tiles. The hexagonal interlocking tiles $(20 \mathrm{~cm}$ sides $\times 10 \mathrm{~cm}$ height) will be grooved and curved inside to give space for "Dubo" covering as shown in Fig. 11. The "Dubo" covering and perviousness will help in reducing the surface temperature during the hot day. This green spot will be the key to the aesthetic of the road.

- Cycle lane: The MMR cycle lane will be an exclusive bicycle facility and is physically 
separated from motor traffic. It is proposed to be one-way, at the road level, just below 3 " of the sidewalk level. The first 750 meters from Hallanchok is proposed to be pervious concrete with remaining as a normal pavement.

\subsubsection{Benefits of a porous sidewalk and cycle lane}

Porous pavement has environmental benefits such as contribution to surface water management, reduction of overall drainage demand, reduction of local heat island effects, controlling of pollutants, groundwater recharge, and prevention of flooding in the road. Similarly, it has safety benefits such as reduction of tire noise, prevention of glare, and reduction of hydroplaning. The porous pavement provided in the sidewalk and cycle lane of the MMR will also aid in increasing the durability of the vehicular lane by facilitating efficient drainage.

\section{Conclusion:}

This study aims at investigating the major issues that are impacting the beauty, sustainability, and livability of Pokhara City (especially near the Lakeside and Phewa Lake area), and proposing recommendation for resolving these issues. Interviews were first conducted to understand the opinion of the local public and experts about the current problem of the city and their opinion about resolving these problems. The interview responses were analyses and a field survey and study were undertaken, finally resulting in the four major recommendations/solutions. The first recommendation is the preservation and development of open space into self-sustaining cohesive community parks, recreational parks and leisure amenities for enhancing the quality of life and supporting social, cultural and aesthetic aspects of the city. The second recommendation is to include the participation and involvement of citizens in all aspects of urban development. The third recommendation is to improve and develop transport infrastructure more attractively, aesthetically and sustainably. The last recommendation is to preserve natural resources such as water,

\section{References:}

[1] D. Chamlagain, "Earthquake scenario and recent efforts toward earthquake vegetation, landscape. For achieving each of these recommendations, four developments were proposed: Phewa Park, Maulik Samudik Uddan, conservation and enhancement of Phewa Lake, and Model Mansawar Road. The direct and indirect benefits such as tourism and economic development, social and cultural development, health and wellbeing, environmental development, and development of the selfsustaining physical infrastructure were discussed. Similarly, the role of these developments in beautifying Pokhara and making it more sustainable, and livable were discussed. As the study was focused on the Lakeside and Phewa Lake area, other similar studies are highly recommended for other regions of the city, finally combining multiple studies to create a comprehensive recommendation or proposal for the beautification of the Pokhara City.

\section{Acknowledgement:}

The authors would like to thank the Nepal ko Yuwa and Daayitwa Fellowship Team for supporting and facilitating this study. We would also like to thank numbers of public and private agencies of Pokhara including the Pokhara Metropolitan City office, Nepal Tourism Board, Department of Survey, Water Resources and Irrigation Development Division for providing the required information and resources for the study and supporting with the interview. This article was not possible without the local support from the local people of Pokhara, especially Shree Krishna Adhikari. The authors also acknowledge the direct and indirect inputs of Binita Pandey, Busan Pkd' Prasain, Aameer Joshi, and other Daayitwa staffs and fellows.

Funding: The project was funded by Daayitwa through the Daayitwa Fellowship program.

Conflicts of Interest: The authors declare no conflict of interest. 
[2] Pokhara, Nepal Metro Area Population 1950-2020. Available:

[3] https://www.macrotrends.net/cities/2335 2/pokhara/population\#: :text=Chart\%20 and $\% 20$ table $\% 20$ of $\% 20$ population, a $\% 2$ $04.73 \% 25 \% 20$ increase $\% 20$ from $\% 20201$ 9.

[4] A. Carr, "Keeping the Town," Berkshire Eagle, 2009.

[5] G.A. Carlino, and A. Saiz, "Beautiful city: Leisure amenities and urban growth," Journal of Regional Science, vol. 59, no. 3, pp.369-408, 2019.

[6] C.L. Choguill, "Ten steps to sustainable infrastructure," Habitat

International, vol. 20, no. 3, pp.389-404, 1996.

[7] D. Ballas, "What makes a 'happy city'?" Cities, vol. 32, pp.S39-S50.

[8] C.C. Marcus, and C. Francis, People places: design guidelines for urban open space. John Wiley \& Sons, 1997.

[9] H.G. Koenig, "Religion, spirituality, and health: The research and clinical implications," International Scholarly Research Notices 2012, 2012.

[10] N. Kumar, "Mudras of the great Buddha: symbolic gestures and postures," ExoticIndiaArt, 2000.

[11] A. McManus, W. Newton, J. Storey, and J. White, "Identifying the health and well-being benefits of recreational fishing," FRDC, vol. 217, pp. 1-64, 2011.

[12] P. Oja, S. Titze, A. Bauman, B.D. Geus, P. Krenn, R.N. Bill, and T. Kohlberger, "Health benefits of cycling: a systematic review," Scandinavian journal of medicine \& science in sports, vol. 21, no. 4, pp. 496-509, 2011.

[13] T. Götschi, J. Garrard, and B. GilesCorti, "Cycling as a part of daily life: a review of health perspectives," Transport Reviews, vol. 36, no. 1 pp. 45-71, 2016.
[14] Y. H. Chang, B. Y. Wu, and C. F. Lai, "The effect of a green energy landscape fountain on water quality improvement," Ecological Engineering, vol. 73, pp. 201-208, 2014.

[15] M. J. Yoo, and I. K. Lee., "Creating musical-fountain shows," IEEE computer graphics and applications, vol. 29, no. 5, pp. 6-13, 2009.

[16] M. Hedblom, B. Gunnarsson, B. Iravani, I. Knez, M. Schaefer, P. Thorsson, and J. N. Lundström, "Reduction of physiological stress by urban green space in a multisensory virtual experiment," Scientific Reports, vol. 9, no. 1, pp. 1-11, 2019.

[17] J. Barton, and M. Rogerson, "The importance of greenspace for mental health," BJPsych International, vol. 14, no. 4, pp. 79-81, 2017.

[18] N.S. Dewi, M. Komatsuzaki, Y. Yamakawa, H. Takahashi, S. Shibanuma, T. Yasue, T. Okayama, A. Toyoda, H. Shimonishi, and S. Sasaki, "Community gardens as health promoters: Effects on mental and physical stress levels in adults with and without mental disabilities," Sustainability, vol. 9, no. 1, p.63, 2017.

[19] Pokhara Sub-Metropolitan, "Pokhara Sub-Metropolitan Development Plan for 2071- 2072 B.S: Annex. no. 12," unpublished.

[20] A. Ganguly, P.K. Chatterjee, and A. Dey, "Studies on ethanol production from water hyacinth-A review," Renewable and Sustainable Energy Reviews, vol. 16, no. 1, pp.966-972, 2012.

[21] A. Das, P. Ghosh, T. Paul, U. Ghosh, B.R. Pati, and K.C. Mondal, "Production of bioethanol as useful biofuel through the bioconversion of water hyacinth (Eichhornia Crassipes)," 3 Biotech, vol. 6, no. 1, p.70, 2016.

[22] Indiamart, Aquatic Plant Harvesters. Available:

https://www.indiamart.com/kelachandra 
-precision-engineers/aquatic-plantharvesters.html.

[23] B. Prajapati, M.B. Jensen, N.O.G. Jørgensen, and N.B. Petersen, "Greywater treatment in stacked multilayer reactors with passive aeration and particle trapping," Water Research, vol. 161, pp.181-190, 2019.

[24] L.T. Arashiro, I. Ferrer, D.P. Rousseau, S.W. Van Hulle and M. Garfí, "The effect of primary treatment of wastewater in high rate algal pond systems: biomass and bioenergy recovery," Bioresource Technology, 280, pp.27-36, 2019
[25] J.B.K. Park, R.J. Craggs, and A.N. Shilton, "Wastewater treatment high rate algal ponds for biofuel production," Bioresource Technology, vol. 102, no. 1, pp.35-42, 2011.

[26] Google, "Map showing the location of Mansawar Road," Google Earth. Available: earth.google.com/web/.

[27] Department of Roads, "Nepal Road Standard 2070," 2013.

[28] S. Chandra, and U. Kumar, "Effect of lane width on capacity under mixed traffic conditions in India," Journal of Transportation Engineering, vol. 129, no. 2, pp.155-160, 2003. 